Article

\title{
Importance of Endocytosis for the Biological Activity of Cedar Virus Fusion Protein
}

\author{
Kerstin Fischer $\mathbb{D}$, Martin H. Groschup and Sandra Diederich *(D) \\ Institute of Novel and Emerging Diseases, Friedrich-Loeffler-Institut, Federal Research Institute for Animal \\ Health, 17493 Greifswald—Insel Riems, Germany; Kerstin.Fischer@fli.de (K.F.); \\ Martin.Groschup@fli.de (M.H.G.) \\ * Correspondence: Sandra.Diederich@fli.de; Tel.: +49-38351-7-1516
}

Received: 26 May 2020; Accepted: 4 September 2020; Published: 8 September 2020

\begin{abstract}
Endocytosis plays a particular role in the proteolytic activation of highly pathogenic henipaviruses Hendra $(\mathrm{HeV})$ and Nipah virus $(\mathrm{NiV})$ fusion $(\mathrm{F})$ protein precursors. These proteins require endocytic uptake from the cell surface to be cleaved by cellular proteases within the endosomal compartment, followed by recycling to the plasma membrane for incorporation into budding virions or mediation of cell-cell fusion. This internalization largely depends on a tyrosine-based consensus motif for endocytosis present in the cytoplasmic tail of $\mathrm{HeV}$ and $\mathrm{NiV} \mathrm{F}$. Given the large number of tyrosine residues present in the F protein cytoplasmic domain of Cedar virus (CedV), a closely related but low pathogenic henipavirus, we aimed to investigate whether CedV F protein undergoes signal-mediated endocytosis from the cell surface controlled by tyrosine-based motifs present in its cytoplasmic tail and whether endocytosis is relevant for its biological activity. Therefore, tyrosine-based signals were mutated, and mutations were assessed for their effect on $\mathrm{F}$ cell surface expression, endocytosis, and biological activity. A membrane-proximal $Y X X \Phi$ motif and a C-terminal di-tyrosine motif are of particular importance for cell surface expression and endocytosis rate. Furthermore, our data strongly indicate the pivotal role of endocytosis for the biological activity of the CedV F protein.
\end{abstract}

Keywords: cedar virus; henipavirus; fusion protein; endocytosis; biological activity

\section{Introduction}

Cedar virus (CedV) belongs to the Henipavirus genus within the Paramyxoviridae family and was first isolated from bat urine samples collected from an Australian Pteropus colony in 2012 [1]. Despite its genetic proximity to the highly pathogenic Hendra (HeV) and Nipah viruses (NiV), CedV has caused only asymptomatic infections in small animal models so far [1,2]. Therefore, research has focused on unraveling the molecular mechanisms leading to differences in the pathogenicity of these closely related viruses. One of the particularities of CedV is an impaired ability of the immunomodulatory phosphoprotein $P$ to counteract the interferon response in cell culture $[1,3]$. Further differences are the receptor usage of the attachment proteins. The generally abundant expression of ephrins as cell entry receptors in numerous tissues and the high conservation among species results in a wide variety of susceptible hosts and a broad cell type tropism, which is fundamental to the zoonotic character and the pathogenesis of henipaviruses. While highly pathogenic $\mathrm{HeV}$ and $\mathrm{NiV}$ are known to utilize ephrin-B2, expressed i.e., in endothelial cells and lung tissue, and ephrin-B3, mainly found in the central nervous system, for cell entry [4-7], CedV is unable to use ephrin-B3 but rather binds to ephrin-B1, which is expressed in different tissues such as salivary glands, esophagus, and lung [8]. Therefore, recent studies have considered the distinct receptor usage of the CedV attachment protein to contribute to its reduced pathogenicity $[8,9]$. 
Besides receptor binding, the interaction of the attachment protein $G$ with the viral fusion protein $F$ is a prerequisite for virus entry into the host cell and virus spread. An indispensable step for the biological activity of fusion proteins and thus, viral infectivity, is the proteolytic cleavage of the precursor protein $\mathrm{F}_{0}$ into the two subunits $\mathrm{F}_{1}$ and $\mathrm{F}_{2}$ [10]. Interestingly, proteolytic activation of $\mathrm{HeV}$ and NiV F protein differs considerably from that of other paramyxoviruses in terms of subcellular localization and protease usage. After transport along the secretory pathway, newly synthesized $\mathrm{HeV}$ and NiV F protein precursors require endocytosis from the cell surface to encounter the activating host cell protease and then become biologically active. Cleavage within the endosomal compartment is then followed by recycling to the cell surface before the incorporation of mature fusogenic $\mathrm{F}_{1}+\mathrm{F}_{2}$ heterodimers into newly budding virions [11-17]. Overall, both viral envelope proteins are important determinants of pathogenicity that need to act in concert to promote virus-cell membrane fusion needed for virus entry as well as cell-cell fusion resulting in syncytia formation and thus, virus spread.

While trafficking through early and late endosomes prior to fusion with cellular membranes plays a critical role in virus entry of many viruses such as influenza virus [18,19], ebolaviruses [20,21], and flaviviruses [22,23], it is dispensable during NiV entry [16]. Moreover, other viruses and their glycoproteins hijack endosomal pathways in order to support their replication in infected cells [24,25]. The viral envelope glycoprotein of human immunodeficiency virus 1 (HIV-1) for instance undergoes endocytosis during the viral replication cycle, which is hypothesized to serve as a mechanism to evade the host immune response by reducing its cell surface expression (reviewed in [26,27]). In addition, trafficking of the HIV-1 envelope glycoprotein through the endocytic recycling compartment has been recently described as an essential step for incorporation into virus particles [28]. Interestingly, endocytosis of herpesvirus glycoproteins has been discussed to play a functional role in cell-cell fusion and in the production of infectious particles by delivering the glycoproteins to the intracellular site where virus assembly takes place $[25,29,30]$. Noteworthy, a recent report even suggests that endocytic trafficking of $\mathrm{HeV} \mathrm{F}$ protein rather than its proteolytic cleavage is a crucial step for efficient $\mathrm{HeV}$ virus-like particle (VLP) assembly [31].

Apart from its importance for the viral replication cycle, endocytosis represents a key process for numerous cellular functions. Characterized by the internalization of the plasma membrane and extracellular molecules from the cell surface into internal membrane compartments, endocytosis is required for many biological events such as maintaining the plasma membrane composition or transporting selected cargo molecules from the cell surface to the interior [32]. Among the different types, clathrin-mediated endocytosis (CME) is the best characterized [33,34]. CME of a transmembrane protein is a highly coordinated process that primarily involves the interaction between the cytoplasmic domain of the protein and intracellular adaptor proteins (AP) that select transmembrane cargo into clathrin-coated pits via association to the clathrin lattice. These adaptor complexes recognize specific sorting motifs within the cytoplasmic tail of the cargo protein that are usually tyrosine- or leucine-based [35-38]. One typical sorting motif in cytoplasmic tails of transmembrane proteins known to interact with specific cytosolic adaptor complex proteins is the tyrosine-based YXX $\Phi$ motif, in which $X$ can be any amino acid and $\Phi$ stands for an amino acid with a large hydrophobic residue. Numerous studies describe YXX $\Phi$ motifs to be recognized by AP2 that selects cargo from the plasma membrane on the one hand and facilitates binding to clathrin on the other hand culminating in CME of selected transmembrane cargo [35-41]. However, adaptor complex proteins are not only known to mediate endocytic uptake from the cell surface. They have also been reported to be involved in distinct transport pathways e.g., from early endosomes to recycling or late endosomes, as well as to lysosomes by adapting to specific motifs [38,42]. Clathrin-mediated endocytic uptake of $\mathrm{HeV}$ and $\mathrm{NiV}$ F proteins strongly depends on a characteristic YXX $\Phi$ motif located in the membrane-proximal part of the cytoplasmic tail as depicted in Table $1[11,12,43]$. Consequently, disruption of this motif led to measurable effects in the biological activity of the proteins [11,12] while another di-tyrosine motif in the C-terminal part of the tail had only negligible effects on NiV F endocytosis [11]. 
Table 1. Boldface and underlined letters highlight (potential) endocytosis signals. Numbers above the sequence indicate the amino acid position. Cytoplasmic tails for $\mathrm{NiV}$ and $\mathrm{HeV} F$ proteins range from amino acid positions 519 to 546, cytoplasmic tail for CedV F is predicted for amino acid positions 517 to 557. Basic aa's that have been shown to be of importance for fusion protein functionality are highlighted in orange.

\begin{tabular}{|c|c|c|}
\hline & 519 & 546 \\
\hline NiV F & \multicolumn{2}{|c|}{... EKKRNTYYSRLEDRRVRPTSSGDL $\underline{Y Y I G T}$} \\
\hline HeV F & \multicolumn{2}{|c|}{... EKKRGNYSRLDDRQVRPVSNGDLYYYIGT } \\
\hline & & 557 \\
\hline CedV F & \multicolumn{2}{|c|}{... KSKHSYKYNKFIDDPDYYNDYKRERINGKASKSNNIYYVGD } \\
\hline
\end{tabular}

The cytoplasmic tail of CedV F protein displays several tyrosine residues that might act as functional endocytosis motifs. In addition to a C-terminal di-tyrosine motif similarly found in $\mathrm{HeV}$ and NiV F protein, a second di-tyrosine motif is present. Interestingly, two degenerate motifs of the $Y x x \Phi$ are obvious: A YxxN motif that has been shown to be a functional endocytosis motif for the spike protein of the Porcine Epidemic Diarrhea Virus [44] and a YxxN motif that has been described to function as an endocytosis signal in the Measles virus hemagglutinin [45]. Thus, in this study, we aimed to investigate the impact of those tyrosine-based motifs on cell surface expression, endocytosis, and biological activity of the protein. Our results suggest a signal-mediated uptake of CedV F protein and confirm the functional importance of a membrane-proximal YXX $\Phi$ and a C-terminal di-tyrosine motif for the biological activity of CedV F protein.

\section{Materials and Methods}

\subsection{Cell Lines, Transfection}

Vero76, MDCK-2 and HeLa cells (Collection of Cell Lines in Veterinary Medicine, Friedrich-LoefflerInstitut, FLI; CCLV-RIE 0228, 1061 and 0082, respectively) were maintained in Dulbecco's modified Eagle's medium (DMEM) supplemented with fetal calf serum (10\%; DMEM10) and incubated at $37^{\circ} \mathrm{C}$. Vero76 and MDCK-2 cells were reverse transfected by using the Lipofectamine 3000 reagent (Invitrogen, Schwerte, Germany) following the manufacturer's protocol. HeLa cells were reverse transfected by using the METAFECTENE ${ }^{\circledR}$ transfection reagent (Biontex, Munich, Germany) according to the manufacturer's instructions.

\subsection{Plasmids and Site-Directed Mutagenesis}

The open reading frame (ORF) of CedV F and G (GenBank accession no. NC_025351.1) were synthesized by GeneArt (Thermo Fisher Scientific Inc., Regensburg, Germany) and subcloned into the pCAGGS expression vector. The ORF of the CedV F gene was codon-optimized for expression in human cells and HA-tagged at the C-terminus and will be designated as wild-type (wt) in the manuscript. Selected tyrosine residues within the cytoplasmic domain of CedV F protein were mutated to alanine by site-directed mutagenesis using the QuikChange Lightning Site-Directed Mutagenesis Kit (Agilent, Waldbronn, Germany) and primers designed according to manufacturer's instructions.

\subsection{Generation of Polyclonal Antibodies}

To obtain a polyclonal antiserum raised against the CedV F protein, a rabbit was immunized subcutaneously three times at three-week intervals with CedV F protein. The antigen was produced in 293T cells as described earlier [46]. Briefly, plasmid DNA encoding for CedV F protein was used to transfect $293 \mathrm{~T}$ cells. At $48 \mathrm{~h}$ post-transfection (p.t.), the supernatant was purified through a $20 \%$ sucrose cushion at $96,000 \times g$ for $2 \mathrm{~h}$ at $4{ }^{\circ} \mathrm{C}$. After washing for $30 \mathrm{~min}$ at $155,000 \times g$, pellets were resuspended in Tris-sodium chloride buffer. Immunization experiments were assessed and approved 
by the competent authority for animal welfare issues of the Federal State of Mecklenburg-Western Pomerania, Germany (license number: LALLF 7221.3-2-042/17).

\subsection{Antibody Uptake Assay}

MDCK-2 cells were reverse transfected with plasmids encoding for parental and mutant CedV F proteins $(1 \mu \mathrm{g} /$ well $)$ in a 24 well plate as mentioned above. At $24 \mathrm{~h}$ p.t., confluent monolayers were washed and incubated without prior fixation with the polyclonal anti-CedV F rabbit serum (1:200 in $0.35 \%$ bovine serum albumin (BSA) in $\mathrm{PBS}^{++}$(PBS with $\left.0.5 \mathrm{mM} \mathrm{MgCl}, 1 \mathrm{mM} \mathrm{CaCl}_{2}\right)(0.35 \%$ $\left.\mathrm{BSA} / \mathrm{PBS}^{++}\right)$). After incubation at $4{ }^{\circ} \mathrm{C}$ for one hour, cells were intensely washed and then either kept on ice or incubated with pre-warmed medium for $30 \mathrm{~min}$ at $37^{\circ} \mathrm{C}$ to allow endocytic uptake. After fixing the cells with $4 \%$ paraformaldehyde (PFA), surface-bound primary antibodies were detected by an Alexa-Fluor (AF) 488-labeled secondary antibody (1:50 in 0.35\% BSA/PBS ${ }^{++}$; LifeTechnologies, Darmstadt, Germany) for $90 \mathrm{~min}$ at $4{ }^{\circ} \mathrm{C}$. After permeabilization with methanol-acetone (1:1) for 10 min, AF 568-labelled secondary antibodies (1:500 in 0.35\% BSA/PBS ${ }^{++}$; LifeTechnologies, Darmstadt, Germany) were added to stain internalized primary antibodies. Images were acquired with an Eclipse Ti-S inverted microscope system and were processed with the ImageJ software version $1.45 \mathrm{~s}$ [47].

\subsection{Metabolic Labeling}

For pulse-chase analysis, MDCK-2 cells transiently expressing CedV F proteins were incubated at $24 \mathrm{~h}$ p.t. for $15 \mathrm{~min}$ with medium lacking cysteine and methionine, followed by incubation with medium containing $\left[{ }^{35} \mathrm{~S}\right]$ cysteine and -methionine (Hartmann Analytic, Braunschweig, Germany) at a final concentration of $100 \mu \mathrm{Ci} / \mathrm{mL}$ for $10 \mathrm{~min}$ (pulse). Then, labeling medium was replaced by a serum-free nonradioactive medium, and cells were incubated at $37^{\circ} \mathrm{C}$ for $2 \mathrm{~h}$ (chase). Afterwards, cells were washed with PBS, followed by cell lysis in radioimmunoprecipitation assay (RIPA) buffer (1\% Triton X-100, 1\% sodium deoxycholate, 0.1\% SDS, $0.15 \mathrm{M} \mathrm{NaCl}, 10 \mathrm{mM}$ EDTA, 50 units $/ \mathrm{mL}$ aprotinin, and $20 \mathrm{mM}$ Tris-HCl, $\mathrm{pH}$ 7.5). Cell lysates were centrifuged for $45 \mathrm{~min}$ at 20,000 $\times g$, and CedV F proteins were immunoprecipitated using a polyclonal anti-HA antibody (H6908; 1:500; Sigma, Darmstadt, Germany). Protein A-Sepharose CL-4B (Sigma, Darmstadt, Germany) suspension was added for another $45 \mathrm{~min}$ followed by several washes of the immune complexes with RIPA buffer. After suspension in sample buffer, proteins were separated on a $12 \%$ polyacrylamide gel under reducing conditions. Dried gels were subjected to autoradiography and analyzed with a CR35 Dark Box Image analyzer (Duerr Medical, Bietigheim-Bissingen, Germany).

\subsection{Colocalization Studies}

For colocalization studies of CedV F and mutants with early endosomes, antibody uptake assays were performed as described above with modifications. Briefly, at $24 \mathrm{~h}$ p.t., CedV F-expressing HeLa cells were incubated with the polyclonal rabbit anti-CedV F serum (1:200) for $1 \mathrm{~h}$ at $4{ }^{\circ} \mathrm{C}$. After washing, cells were shifted to $37^{\circ} \mathrm{C}$ for 5 or $30 \mathrm{~min}$ to allow endocytosis to occur. Then, surface-bound primary antibodies were blocked with a horseradish peroxidase (HRP)-conjugated secondary antibody (1:50; LifeTechnologies, Darmstadt, Germany). After fixation with 2\% PFA for $20 \mathrm{~min}$ and permeabilization with $0.2 \%$ Triton X-100 in PBS, a mouse anti-human early endosomal antigen 1 (EEA-1) antibody (1:50; BD Biosciences, Heidelberg, Germany) was added for $1 \mathrm{~h}$ at $4{ }^{\circ} \mathrm{C}$ for staining of early endosomes. Internalized primary rabbit antibodies were stained with AF 488-conjugated secondary antibodies (1:500; LifeTechnologies, Darmstadt, Germany). Primary mouse antibodies bound to EEA-1 were detected with AF 568-conjugated secondary antibodies (1:500; LifeTechnologies, Darmstadt, Germany). Cell nuclei were counterstained with 4',6-Diamidin-2-phenylindol (DAPI). Representative images were recorded with a confocal laser scanning microscope (Leica SP5) and processed with the ImageJ software version $1.45 \mathrm{~s}$ [47]. 


\subsection{Surface Biotinylation and Western Blot Analysis}

MDCK-2 cells were transfected with plasmid DNA encoding either CedV F or mutant CedV F protein genes. At $24 \mathrm{~h}$ p.t., cells were washed and incubated twice with $2 \mathrm{mg} / \mathrm{mL}$ EZ-Link ${ }^{\circledR}$ Sulfo-NHSLC-Biotin (ThermoFisher Scientific, Waltham, MA, USA) for $20 \mathrm{~min}$ at $4{ }^{\circ} \mathrm{C}$. Following cell lysis, F proteins were immunoprecipitated overnight using NeutrAvidin Agarose Resin (ThermoFisher Scientific, Waltham, MA, USA) according to the manufacturer's protocol. Proteins were separated on a 10\% SDS-gel under reducing or non-reducing conditions and then transferred onto nitrocellulose. Biotinylated CedV F proteins were detected by incubation with the HA-tag specific rabbit antibody H6908 (dilution 1:2,000 in PBS-Tween (0.05\%)) followed by labeling with anti-rabbit HRP-conjugated secondary antibodies (1:5.000). Under non-reducing conditions, HRP-labeled Concanavalin A (ConA; Sigma-Aldrich, Darmstadt, Germany, 1:1,000 in PBS containing 0.05\% (v/v) TWEEN 20, $1 \mathrm{mM} \mathrm{CaCl}_{2}$, $1 \mathrm{mM} \mathrm{MnCl}$, and $1 \mathrm{mM} \mathrm{MgCl} 2$ for $16 \mathrm{~h}$ at $20{ }^{\circ} \mathrm{C}$ ) was used to stain NeutrAvidin-precipitated surface glycoproteins, which served as a loading control and as a reference to compare CedV $\mathrm{F}_{0}$ protein intensities. Proteins were visualized using a chemiluminescent substrate (Clarity Western ECL substrate, Bio-Rad, Feldkirchen, Deutschland) and the Bio-Rad Molecular Imager Chemi Doc ${ }^{\mathrm{TM}}$ XRS+ in combination with the Image Lab software (Bio-Rad, Feldkirchen, Deutschland, Version 6.0.1).

\subsection{Quantification of Endocytosis Rate by MESNA Reduction}

MDCK-2 cells transiently expressing either CedV F or mutant F proteins were surface labeled with cleavable EZ-Link sulfo-NHS-SS-biotin (ThermoFisher Scientific, Waltham, MA, USA) at $4{ }^{\circ} \mathrm{C}$. Then, wells were flooded with pre-warmed DMEM $\left(37^{\circ} \mathrm{C}\right)$ and shifted to $37^{\circ} \mathrm{C}$ for either $5,15,30$, or 90 min to allow endocytosis to occur. After rapid cooling to $4{ }^{\circ} \mathrm{C}$, biotin still bound to the cell surface was cleaved by a membrane-impermeable reducing agent, 2-mercaptoethane-sulfonic acid sodium salt (MESNA; $50 \mathrm{mM}$ in MESNA buffer (50 mM Tris, $\mathrm{pH}$ 8.5, $100 \mathrm{mM} \mathrm{NaCl}, 2.5 \mathrm{mM} \mathrm{CaCl} 2)$ ) a total of three times for $20 \mathrm{~min}$. One sample was kept on ice and was neither incubated at $37^{\circ} \mathrm{C}$ nor cleaved with MESNA and thus served as the surface biotinylation control to determine the total amount of biotinylated protein (control). After cell lysis in RIPA buffer, CedV F and CedV mutant F proteins were immunoprecipitated using the $\mathrm{H} 6908$ antibody as described above and separated by SDS-PAGE under non-reducing conditions. Transfer to nitrocellulose was followed by the detection of biotinylated proteins with HRP- labeled streptavidin and a chemiluminescent substrate. Protein bands were quantified using ImageLab software (version 6.0.1). Mean internalization rates per min were calculated as the ratio of band intensities from internalized, intracellular biotinylated protein after 5, 15, 30, and 90 min and total surface-labeled F protein (control, 50\%) divided by 5, 15, 30, and $90 \mathrm{~min}$, respectively.

\subsection{Fusion Assay}

A total of $4 \times 10^{5}$ Vero76 cells or $3 \times 10^{5}$ MDCK-2 cells were co-transfected with expression plasmids encoding for CedV G ( $0.5 \mu \mathrm{g} /$ well $)$ and either F or mutant F proteins $(0.5 \mu \mathrm{g} /$ well $)$. At $48 \mathrm{~h}$ p.t., cells were fixed with ethanol and stained with 1:10-diluted Giemsa staining solution. Representative images (20x magnification) were recorded with an inverted microscope.

\subsection{Luciferase Reporter Gene-Based Fusion Assay}

Vero76 cells were reverse transfected with expression plasmids encoding for CedV G and either $\mathrm{F}$ or mutant F proteins as described above and seeded in 24-well plates. In addition, pCITE Renilla ( $200 \mathrm{ng} /$ well), a vector containing the renilla luciferase gene under the control of the T7 promoter, was co-transfected. In parallel, Vero76 cells were reverse transfected with the pCAGGS T7 polymerase vector. At 27 h p.t., Vero76 cells expressing the T7 polymerase were washed twice with EDTA-containing PBS (5 mM), detached and added to the cells pre-transfected with pCAGGS CedV F and G and pCITE Renilla to allow fusion to proceed. After $3 \mathrm{~h}$, cells were lysed using Lysis Buffer (pjk, GmbH, 
Kleinblittersdorf, Germany) and luciferase activity was measured by adding Renilla Glow substrate (pjk GmbH, Kleinblittersdorf, Germany) according to the manufacturer's instructions. Samples were tested in duplicate in three independent experiments. Reporter activity detected upon co-transfection of the parental CedV F with CedV G protein was set to one, which served as a reference point for fusion activity. Reporter activities measured for the fusion of mutant CedV F proteins were used to calculate their fusion activity in relation to the parental protein. Background activity of the luciferase reporter was assessed with cells transfected with pCAGGS CedV G and pCITE Renilla only overlaid with T7 polymerase expressing cells.

\section{Results}

Endocytosis of $\mathrm{HeV}$ and NiV F protein precursors represents a critical step to gain biological activity, and thus, viral infectivity. In order to investigate whether CedV F protein similarly undergoes endocytosis from the cell surface, we performed a qualitative antibody uptake assay as described previously [11]. Therefore, MDCK-2 cells were transfected with plasmid DNA encoding for the CedV $\mathrm{F}$ protein. At $24 \mathrm{~h}$ p.t. without prior fixation, cell-surface expressed CedV F protein was labeled with CedV F protein-specific antibodies. Next, cells were either kept on ice or shifted to $37^{\circ} \mathrm{C}$ for $30 \mathrm{~min}$ to allow endocytosis to occur. Surface-bound antibodies were then detected with an AF 488-conjugated secondary antibody that was added in excess to saturate surface-bound primary antibodies. Subsequent permeabilization allowed the staining of intracellular F protein-antibody complexes with an AF 568-conjugated antibody. After incubation at $37^{\circ} \mathrm{C}$, cells expressing the CedV $F$ protein showed both green surface staining and multiple red fluorescent intracellular vesicles indicating endocytosis of the labeled CedV F protein (Figure 1). In contrast, we observed only green fluorescent signals of $\mathrm{F}$ proteins in cells that were kept on ice suffering a temperature-related inhibition of endocytosis.

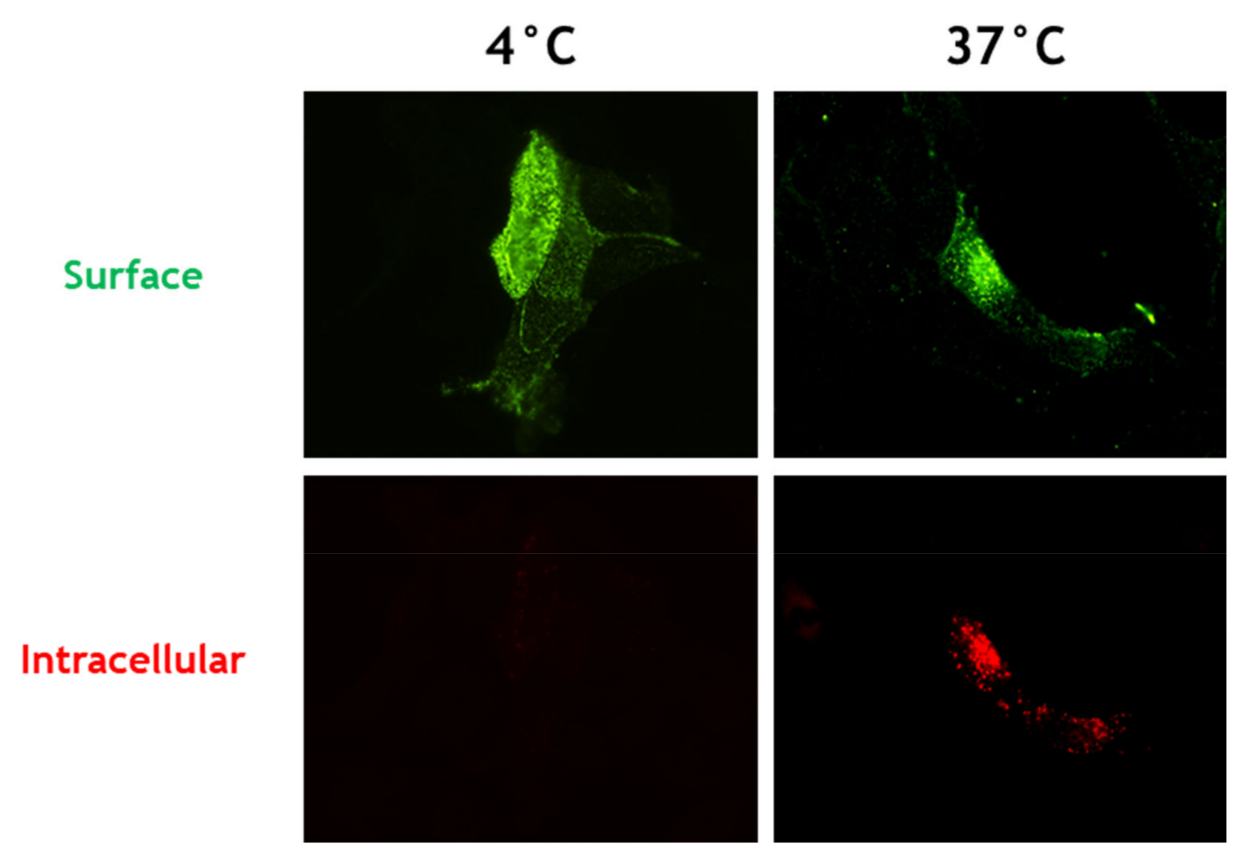

Figure 1. Endocytosis of CedV F protein in MDCK-2 cells. At 24 h p.t., CedV F-expressing MDCK-2 cells were incubated with a CedV F-specific rabbit antiserum to label surface-expressed F proteins. Then, the cells were shifted to $37^{\circ} \mathrm{C}$ for $30 \mathrm{~min}$ to allow endocytosis to occur. AlexaFluor (AF) 488-conjugated secondary antibodies visualized surface-bound primary antibodies. After fixation and permeabilization, AF 568-conjugated secondary antibodies were used to stain internalized primary antibody-CedV F protein complexes. Magnification, $\times 60$. $n=3$. 
To evaluate the functional importance of the tyrosine-based motifs within the CedV F protein cytoplasmic tail for endocytosis, we generated seven F protein mutants by tyrosine to alanine substitution (Figure 2). We constructed mutants encoding either single (e1-e5) or multiple (e3, e6) mutations as well as one mutant devoid of all putative endocytosis signals (e7) to investigate potentially additive effects of these mutated motifs (Figure 2). Apart from a classical YXX $\Phi$ motif in the membrane-proximal region $\left(\mathrm{Y}_{524} \mathrm{XXF}\right.$, Figure 2), we chose to also mutate the tyrosine residue at amino acid position $522\left(\mathrm{Y}_{522} \mathrm{XXN}\right.$, Figure 2) since a similar motif present in the cytoplasmic domain of Measles virus hemagglutinin has been described earlier to affect basolateral sorting and internalization of the protein [45].

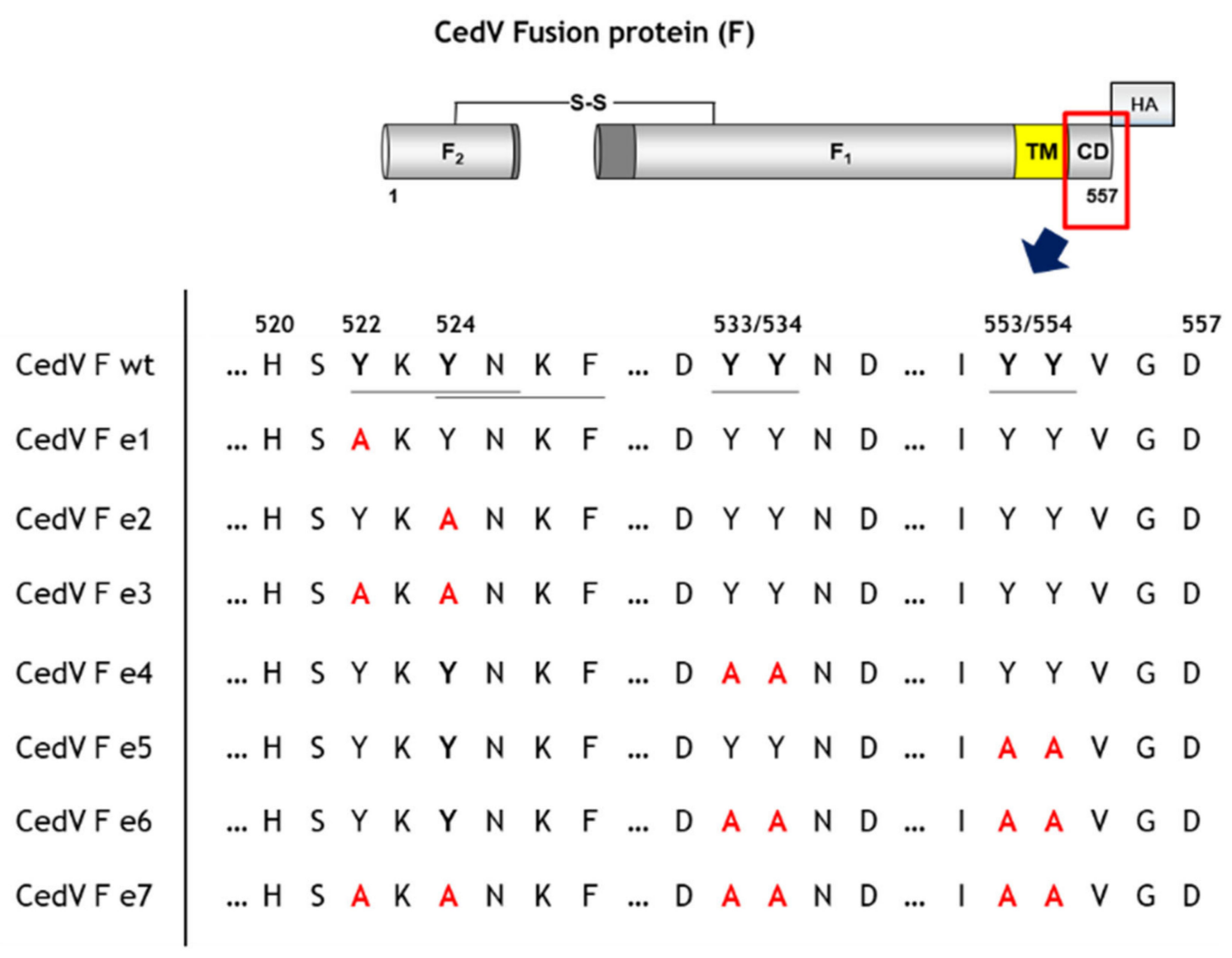

Figure 2. Schematic overview of the cytoplasmic tail mutants of CedV F protein generated in this study. Tyrosine-based putative endocytosis motifs are underlined. $\mathrm{F}_{1}$ : CedV F protein subunit $\mathrm{F}_{1} ; \mathrm{F}_{2}$ : CedV F protein subunit $\mathrm{F}_{2}$; TM: transmembrane domain; $\mathrm{CD}$ : cytoplasmic domain; HA: HA-tag at the C-terminus of the $\mathrm{F}_{1}$ subunit; $\mathrm{S}$-S: di-sulfide bond. wt: wild-type.

To assess whether these mutations have an impact on F protein synthesis, we compared expression efficiencies using a pulse-chase analysis. At $24 \mathrm{~h}$ p.t., MDCK-2 cells were labeled metabolically with [35] cysteine and -methionine for $15 \mathrm{~min}$. After pulse-labeling, cells were incubated for $2 \mathrm{~h}$ followed by immunoprecipitation and SDS-PAGE under reducing conditions. We observed similar amounts of expression for parental and mutant $\mathrm{F}$ proteins within $2 \mathrm{~h}$ demonstrating that mutations within the cytoplasmic tail do not impair protein synthesis (Figure 3). However, although mutant e7 was expressed at similar levels, proteolytic processing was much less efficient. We generated additional $\mathrm{F}$ protein constructs combining selected mutations of particular motifs $(e 8=e 3+e 4 ; e 9=e 3+e 5)$. Since these mutants displayed no differences in proteolytic processing to F wt (Supplementary Figure S1), they were not included in subsequent analyses. Together, these findings suggest that proteolytic activation of the CedV F protein is markedly impaired upon the simultaneous disruption of all tyrosine-based motifs. 


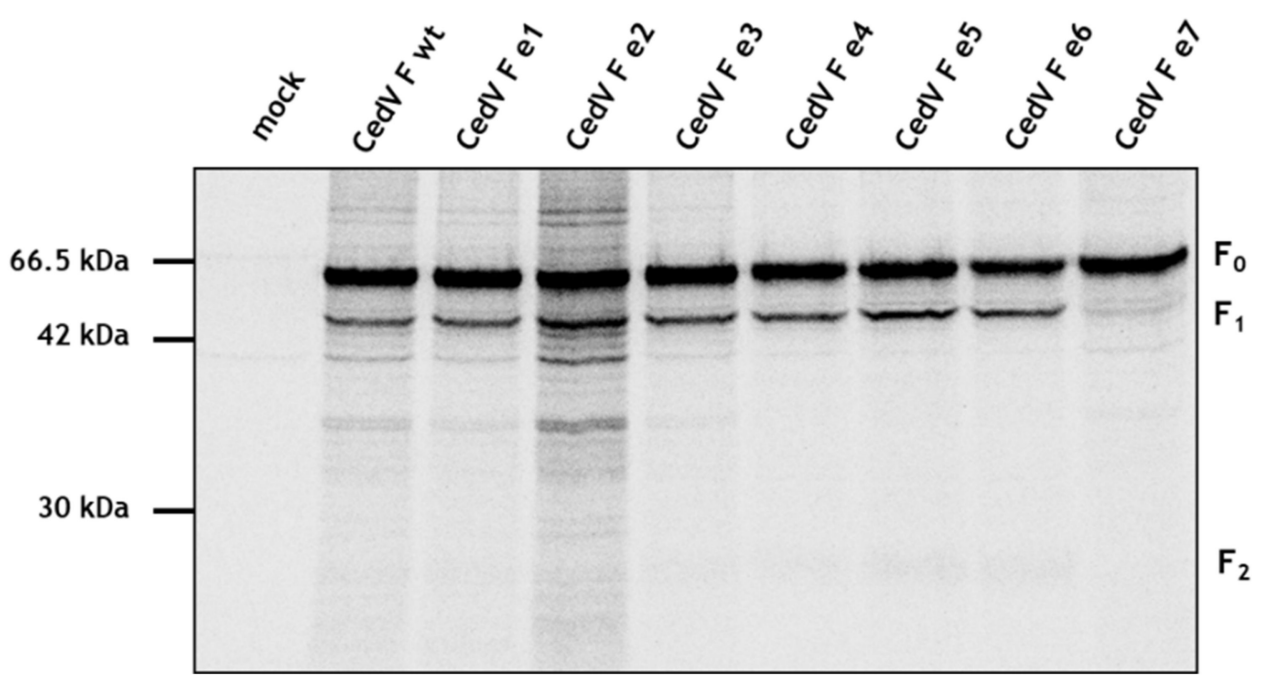

Figure 3. Effect of cytoplasmic tail mutations on CedV F protein expression and cleavage. At 24 h p.t., MDCK-2 cells expressing different CedV F proteins were metabolically labeled for $15 \mathrm{~min}$ (pulse) and then incubated for $2 \mathrm{~h}$ in serum-free nonradioactive medium (chase). After immunoprecipitation of $\mathrm{F}$ proteins from cell lysates and separation on a $12 \%$ SDS-gel under reducing conditions, samples were analyzed by autoradiography. $n=2$; wt: wild-type.

$\mathrm{HeV}$ and $\mathrm{NiV} F$ proteins are known to be cleaved within the endosomal compartment. In analogy, blocking clathrin-mediated endocytosis by addition of chlorpromazine also inhibited proteolytic processing of CedV F protein (see Supplementary Figure S2) demonstrating that endocytosis is a prerequisite for CedV F cleavage. Thus, inefficient cleavage of CedV mutant e7 might result from an inability to undergo endocytosis. In order to study the effects of single and multiple cytoplasmic tail mutations on CedV F protein endocytosis, we performed another antibody uptake experiment as described above using all generated mutants. After a period of $30 \mathrm{~min}$ at $37^{\circ} \mathrm{C}$, we observed intracellular red vesicles for all mutants except mutant e7 with all tyrosine-based motifs disrupted (Figure 4a). Disruption of a single motif such as YXXN (mutant e1) or YXXF (mutant e2), the di-tyrosine motifs (mutants e4, e5) as well as the combination of several mutated tyrosine residues (mutants e3, e6) displayed no difference in comparison to the fluorescent signals of the parental CedV F protein (Figure 1). The qualitative finding of red fluorescent vesicles indicates the internalization of mutants e1 to e6 from the cell surface while endocytosis of mutant e7 was strongly impaired after $30 \mathrm{~min}$ of endocytosis.

To further understand the effects of single and multiple mutations on endocytosis, we next aimed to quantify the internalization of the different CedV F proteins and compare their endocytosis rate with the wt CedV F protein in a semi-quantitative biotin internalization assay. Moreover, this assay allowed us to demonstrate that the internalization of F proteins is not induced by antibody cross-linking. Briefly, we performed a surface biotinylation assay using a cleavable NHS-SS biotin derivative. Using the membrane-impermeable reducing agent MESNA, residual biotin that was not internalized from the cell surface after incubation at $37^{\circ} \mathrm{C}$ for different periods can be cleaved. Cell lysis, immunoprecipitation of F proteins, and Western blot using Streptavidin-HRP were performed with subsequent detection and quantification of intracellular biotinylated F proteins. The amount of internalized protein was quantified by comparison to F-expressing cells that were neither incubated at $37^{\circ} \mathrm{C}$ nor treated with MESNA, therefore, representing the total amount of biotinylated F proteins (Ctr lane, Figure $4 \mathrm{~b}$ ). Since internalization rates did not appear to be linear over time, endocytosis of biotinylated proteins is displayed additionally as a function of the time in Figure 4c. More than $80 \%$ of the parental CedV F protein was internalized after $30 \mathrm{~min}$ (Figure $4 \mathrm{~b}, \mathrm{c}$ ). Similarly, mutant e1 carrying a substitution of a single tyrosine residue at aa position 522 as well as the di-tyrosine motif mutants e4, e5, and e6 displayed only a marginal decrease in internalization compared to the parental F protein. 
Interestingly, mutation of the $Y X X \Phi$ motif (mutant e2 and e3) clearly decreased internalization with weak signals detectable after a period of 15 to $30 \mathrm{~min}$ at $37^{\circ} \mathrm{C}$ (Figure $4 \mathrm{~b}$ ). However, the strongest effects were observed for mutant e7. Here, biotinylated mutant e7 was only detected after 90 min of incubation at $37^{\circ} \mathrm{C}$ (Figure $4 \mathrm{~b}$ ) leading to a drastically reduced internalization rate over time in contrast to the parental $\mathrm{F}$ protein and the other mutants (Figure 4c). An antibody uptake assay of CedV F proteins including a co-staining of endosomal marker protein early endosomal antigen-1 (EEA1) in HeLa cells confirmed the delayed uptake of mutants e 2 and e3. After 5 min at $37^{\circ} \mathrm{C}$, we observed no internalization of CedV F mutants e2 and e 3 and thus, no co-localization with EEA1 (Figure 4d). However, both mutants co-localized with EEA1 after $30 \mathrm{~min}$. In contrast, the parental F protein showed intracellular staining and co-localization with EEA1 as early as $5 \mathrm{~min}$ after the shift to $37^{\circ} \mathrm{C}$ (Figure $4 \mathrm{~d}$ ).

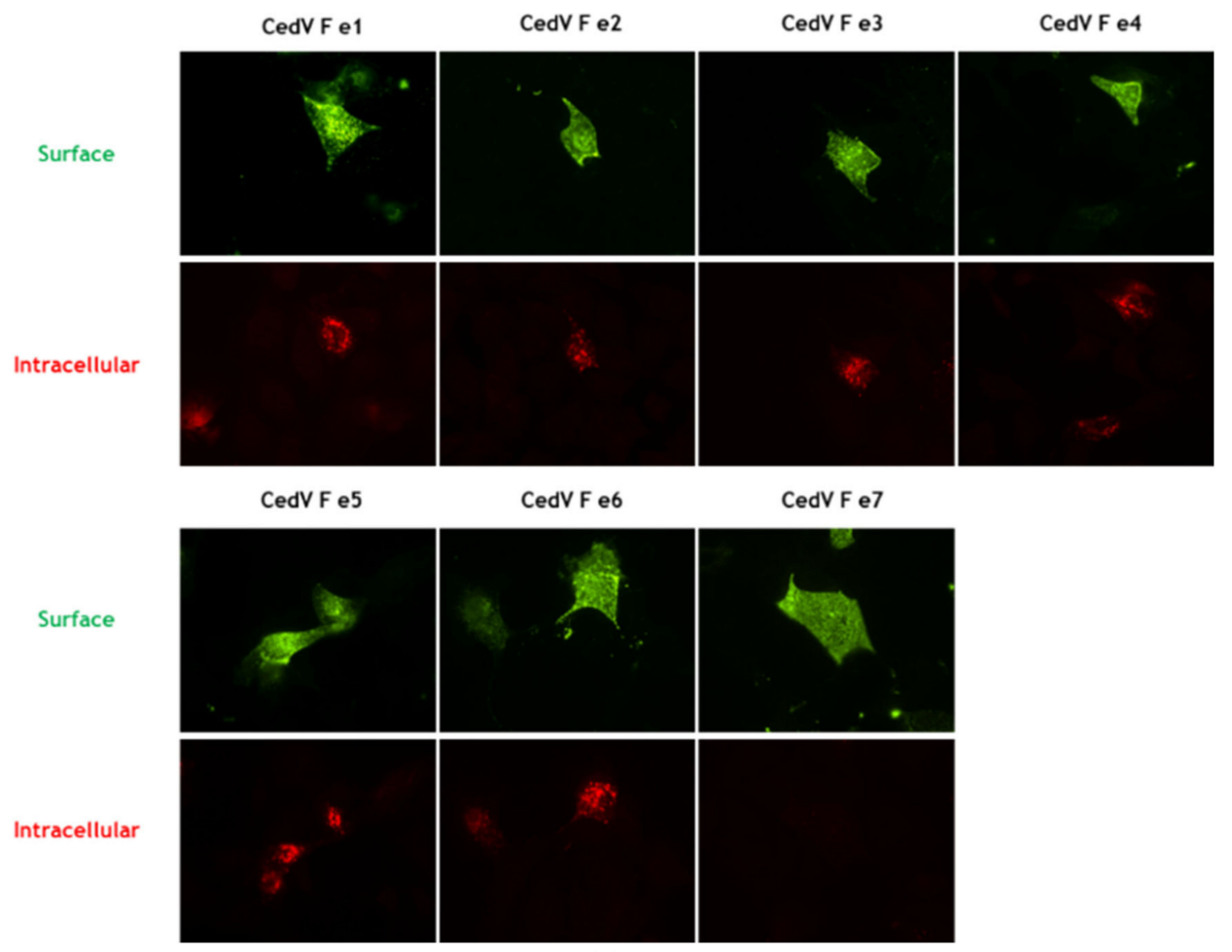

(a)

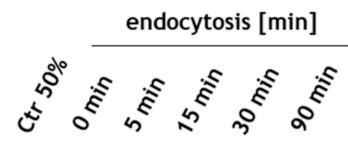

CedV $F_{w t}$

CedV $F_{\mathrm{e} 1}$

CedV $\mathrm{F}_{\mathrm{e} 2}$

CedV $\mathrm{F}_{\mathrm{e} 3}$

CedV $\mathrm{F}_{\mathrm{e} 4}$

CedV $\mathrm{F}_{\mathrm{e} 5}$

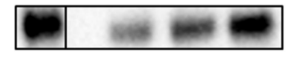

CedV $\mathrm{F}_{\mathrm{e} 6}$

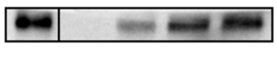

CedV $\mathrm{F}_{\mathrm{e}}$

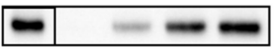

(b)

Figure 4. Cont. 


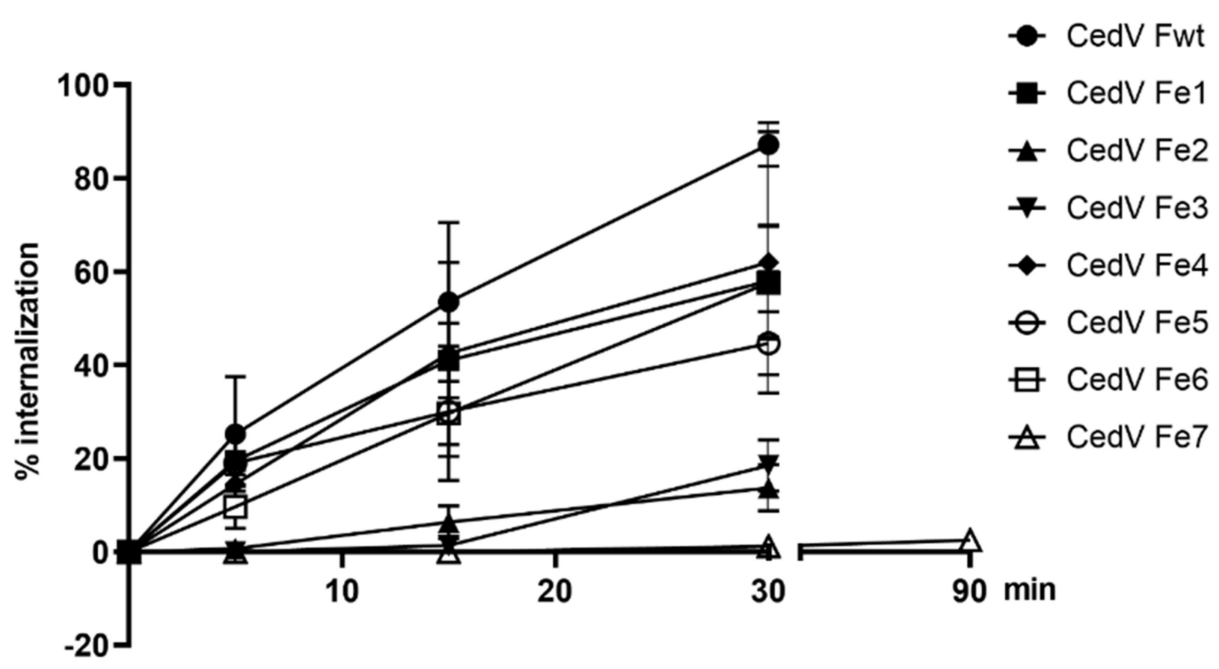

(c)
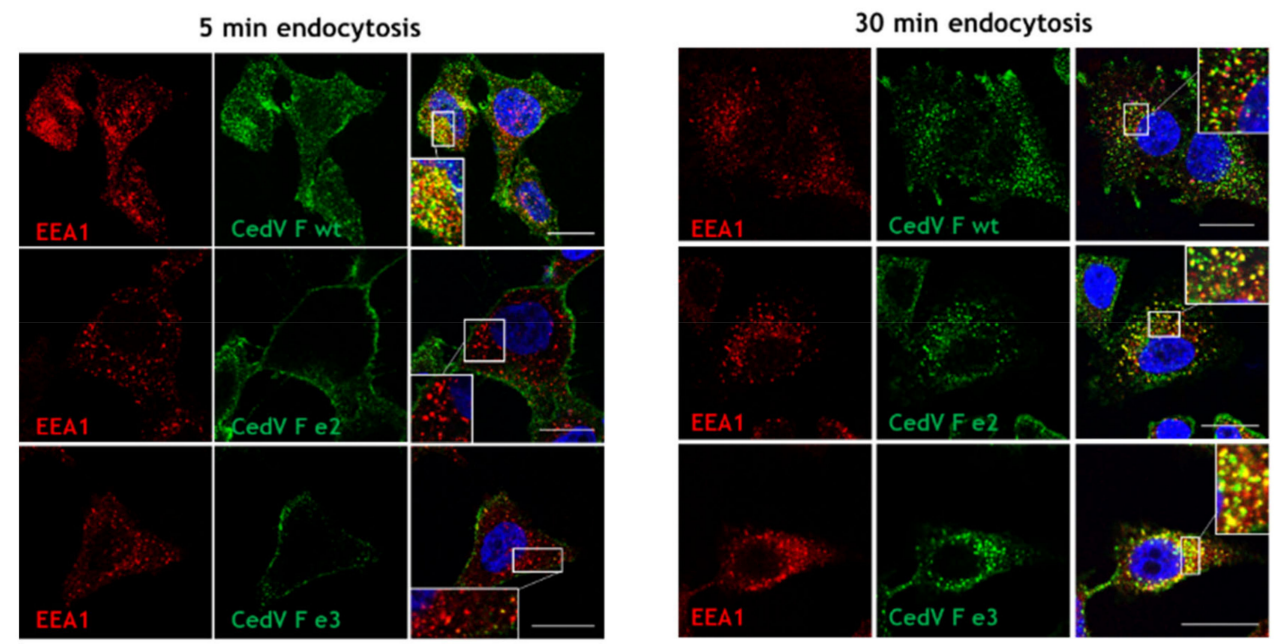

(d)

Figure 4. Endocytosis of CedV F proteins in MDCK-2 cells. (a) Antibody uptake assay of mutant CedV F proteins. MDCK-2 cells were transfected with plasmids encoding the indicated CedV F protein mutants. At $24 \mathrm{~h}$ p.t., a CedV F-specific rabbit antiserum was used to label surface-expressed F proteins at $4{ }^{\circ} \mathrm{C}$. Then, the cells were shifted to $37^{\circ} \mathrm{C}$ for $30 \mathrm{~min}$ to allow endocytosis to occur. AF 488-conjugated secondary antibodies visualized surface-bound primary antibodies. After fixation and permeabilization, AF 568-conjugated secondary antibodies were used to stain internalized primary antibody-CedV F protein complexes. Magnification, $\times 60 . n=2$. (b) At 24 h p.t., CedV F-expressing cells were surface-labeled with cleavable NHS-SS biotin at $4{ }^{\circ} \mathrm{C}$ followed by a shift to $37^{\circ} \mathrm{C}$ for the indicated times allowing endocytosis to occur. Residual biotin was then cleaved from the cell surface using MESNA. To quantify the amount of surface-biotinylated proteins that underwent endocytosis in a certain time, samples were compared to the total amount of surface-biotinylated control cells (Ctr) that were neither incubated at $37^{\circ} \mathrm{C}$ nor treated with MESNA. Following cell lysis, F proteins were immunoprecipitated and samples were separated under non-reducing conditions. After transfer to nitrocellulose, biotinylated proteins were detected with peroxidase-conjugated streptavidin and chemiluminescence. The control lane represents $50 \%$ of the total amount of biotinylated F proteins (Ctr 50\%). One representative blot is shown for each CedV F protein variant. ( $n=3 ; n=2$ for mutants e1, e3, and e4). wt: wild-type (c) CedV F protein internalization in percentage (\%) per minute. To quantify the internalization rate, the percentages of internalized F protein amounts measured in the experiment shown in Figure $4 \mathrm{~b}$ are displayed as a function of the time of incubation at $37^{\circ} \mathrm{C}$. Error bars represent the standard error of the mean. (d) Intracellular localization of wt and mutant CedV F proteins in MDCK-2 
cells after 5 and $30 \mathrm{~min}$ at $37^{\circ} \mathrm{C}$. An antibody uptake assay of CedV F proteins was performed as described above with slight modifications. After the endocytosis step, surface-bound primary antibodies were blocked using a peroxidase-labeled secondary antibody while internalized primary antibodies were detected with AF 488-conjugated rabbit-specific secondary antibodies after fixation and permeabilization. Likewise, early endosomes were visualized with a primary antibody against the early endosomal antigen-1 (EEA1) and a mouse-specific AF568-conjugated secondary antibody. Scale bars indicate $20 \mu \mathrm{m}$. Representative images from two independent experiments are displayed $(\mathrm{n}=2)$. Inserts show magnifications of indicated areas. Magnification, $\times 63$.

Since differences in the internalization rate might directly affect cell surface expression, we next performed a surface biotinylation assay of F-expressing MDCK-2 cells followed by immunoprecipitation of biotinylated proteins and detection of the HA-tagged proteins in Western blot. In accordance with the antibody uptake assay and the MESNA reduction, we observed that all F proteins reached the cell surface (Figure 5). However, comparing the cell surface expression of all F proteins under non-reducing conditions, the amount of $\mathrm{F}_{0}$ differed distinctly between the parental CedV F protein and some mutant $\mathrm{F}$ proteins (Figure $5 \mathrm{a}$ ). In all biotinylation assays performed mutant $\mathrm{e} 1$ displayed a cell surface expression similar to the parental CedV F protein, while surface expression of mutants e2-e5 was slightly increased. In contrast, the average level of cell surface expression of mutants, e6 and e7 was substantially higher. For mutant e7, we detected up to 2.5-fold more $\mathrm{F}_{0}$ on the cell surface than for the parental $F$ protein. Under reducing conditions (Figure $5 b$ ), both the $F_{0}$ precursor and the subunit $\mathrm{F}_{1}$ were detected for all $\mathrm{F}$ proteins analyzed, indicating that all of them were proteolytically cleaved despite mutations in their cytoplasmic tails. For the parental F protein as well as for mutant e1-e6, quantification of band intensities revealed that more cleavage product $F_{1}$ than inactive precursor $F_{0}$ is found at the cell surface. However, mutant $\mathrm{e}$ rather displayed a reversed cleavage ratio, with less $\mathrm{F}_{1}$ present on the cell surface indicating a reduced amount of cleaved F protein. Although internalization of mutants e2 and e3 was shown to be clearly delayed in the biotin internalization assay, proteolytic activation and surface expression of these mutants still seemed to reach levels comparable to the parental $\mathrm{F}$ protein after $24 \mathrm{~h}$ p.t.

Finally, to assess whether any of the observed effects influence the biological activity of the F proteins, syncytium formation was analyzed in a fusion assay. At $48 \mathrm{~h}$ p.t., co-expression of the parental CedV F and CedV G proteins resulted in the formation of multinucleated syncytia in MDCK2 cells (Figure 6a) and Vero76 cells (Figure 6b). Mutant CedV F e1 and e4 induced syncytium formation comparable to the parental F protein. Surprisingly, despite their reduced endocytosis rate but parental F-like cell surface expression, co-expression of mutant $\mathrm{e} 2$ or e3 with CedV G led to a hyperfusogenic phenotype forming syncytia that were markedly increased in number and size (Figure $6 a, b)$. Interestingly, fusogenicity of mutant e5 and e6 displaying an increased surface expression compared to the parental $\mathrm{F}$ protein was slightly enhanced while fusion activity of endocytosis-deficient mutant e7 was strongly impaired in both cell lines tested (Figure $6 a, b$ ). In addition, we quantified these differences using a luciferase reporter gene-based fusion assay in Vero76 cells after $24 \mathrm{~h}$ p.t. The hyperfusogenic phenotype of mutant $\mathrm{e} 2$ and e3 displayed a 4- and 6.5-fold increase in measurable luciferase reporter activity compared to the parental F protein (Figure 6c). Co-expression of CedV G protein with mutant e5 still resulted in a 2.5-fold increase in reporter activity in Vero76 cells (Figure 6c). A marked decrease in reporter activity was confirmed for mutant e7. Since fusion activity is sensitive to the cell surface expression of both glycoproteins and to exclude that observed effects in fusogenicity were due to an altered cell-surface expression of CedV G protein, we performed a surface biotinylation assay in MDCK-2 cells co-transfected with CedV G and wt or mutant CedV F proteins. As depicted in Supplementary Figure S3, both F and G can be detected at the cell surface. Irrespective of the (mutant) F protein combination, the $\mathrm{G}$ expression at the cell surface seems to be similar suggesting that observed effects in fusion activity are not related to differences in CedV G cell surface expression. Taken together, these findings demonstrate that a membrane-proximal $Y X X \Phi$, as well as a C-terminal di-tyrosine motif in 
the CedV F protein cytoplasmic tail, are of functional relevance for endocytosis and biological activity of the protein.

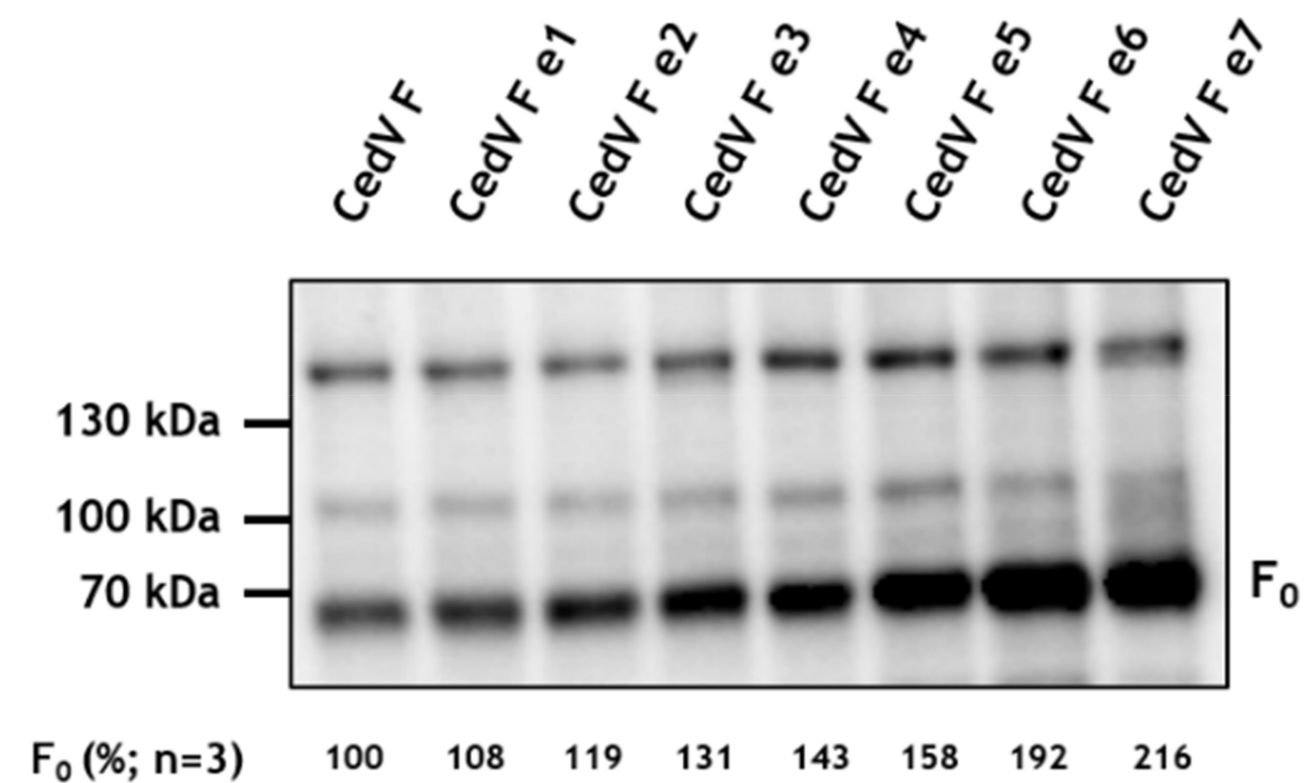

(a)

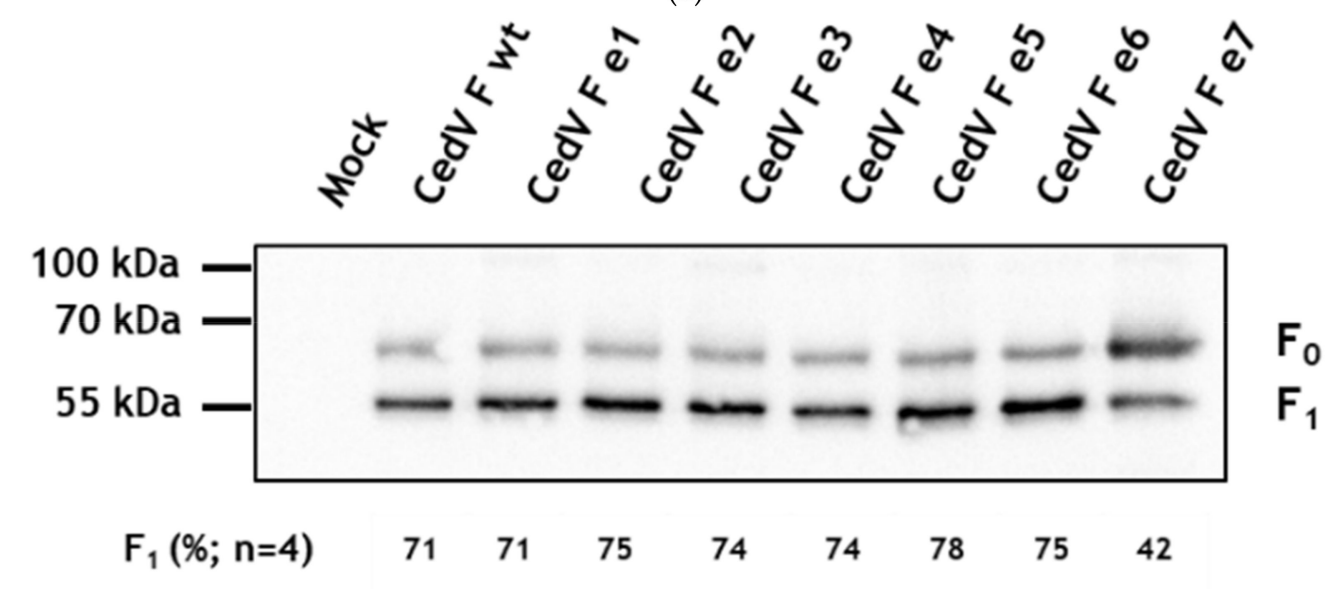

(b)

Figure 5. Cell surface expression of CedV F proteins. At 24 h p.t., MDCK-2 cells expressing F proteins were surface-labeled with biotin on ice. After cell lysis, biotinylated proteins were immunoprecipitated using NeutrAvidin beads and subjected to SDS-PAGE under non-reducing (a) and reducing (b) conditions. Precipitated F proteins were visualized using an antibody against the HA-tag (H6908), HRP-labeled secondary antibodies, and chemiluminescence. In (a), ConA staining is used as a loading control. Representative blots are shown from (a) three or (b) four independent experiments. The amount of $F_{0}$ and $F_{1}$ protein (in (a) \% of CedV $F_{0}$ protein with the parental $F$ protein set to $100 \%$ or $(\mathbf{b}) \%$ of $F_{1}$ protein) is calculated as the mean of three or four independent experiments, respectively. wt: wild-type. 


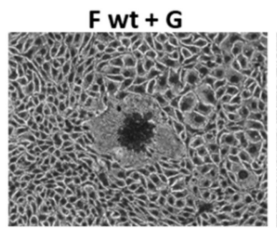

F e4 + G

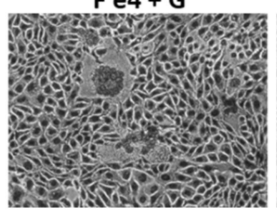

F wt + G

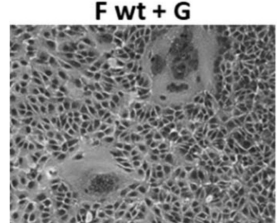

$\mathrm{F} \mathrm{e} 4+\mathrm{G}$

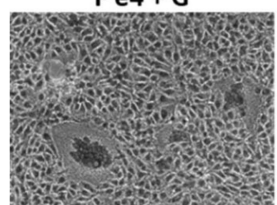

$F e 1+G$

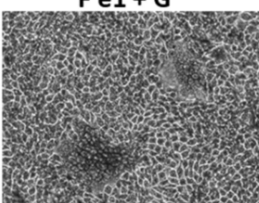

F e5 + G

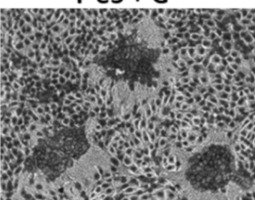

$\mathrm{Fe}+\mathrm{G}$

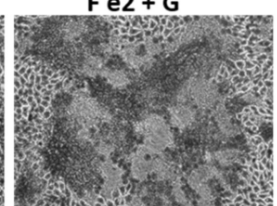

F e6 + G

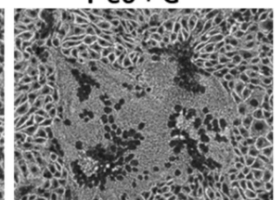

(a)

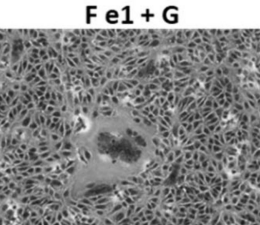

$\mathrm{F} \mathrm{e5}+\mathrm{G}$

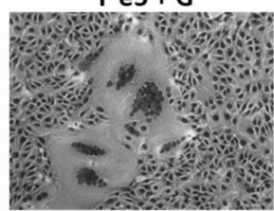

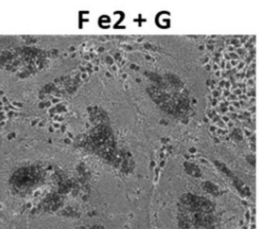

F e $6+\mathbf{G}$

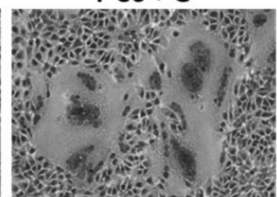

(b)

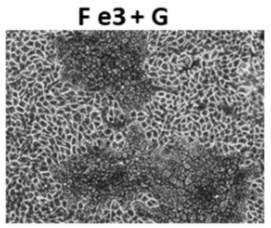

F e7 + G

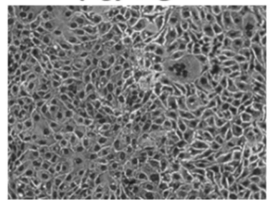

$\mathrm{Fe}+\mathrm{G}$

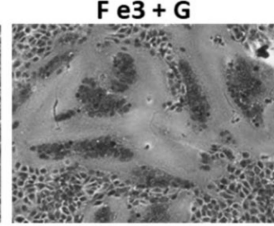

$\mathrm{F} \mathrm{e7+G}$
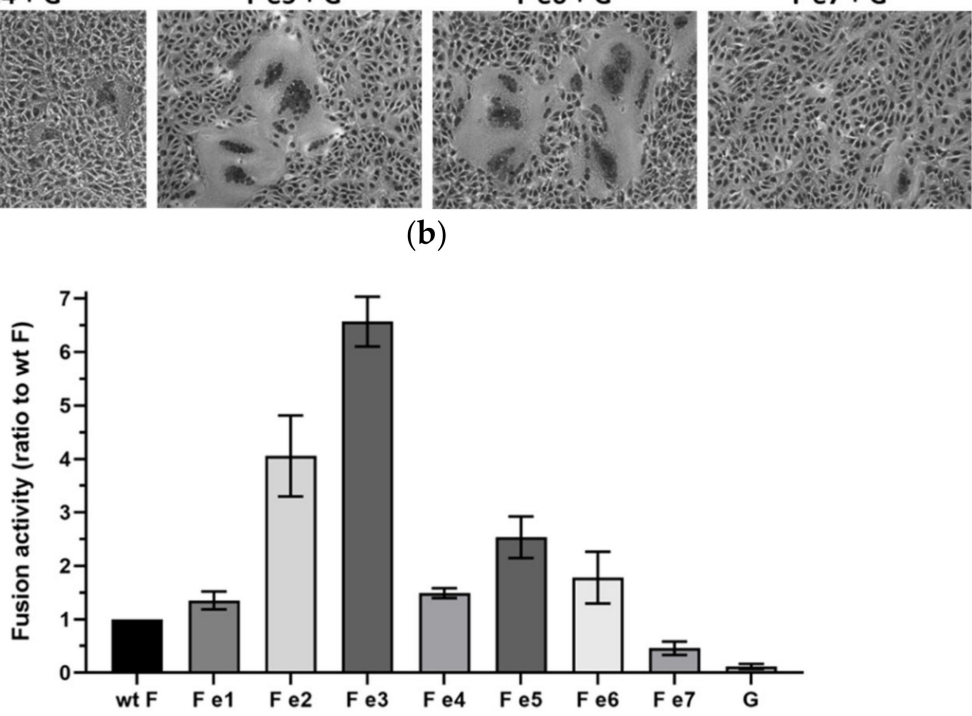

(c)

Figure 6. Effect of cytoplasmic tail mutations on CedV glycoprotein-mediated fusion activity. Syncytium formation in (a) MDCK-2 and (b) Vero76 cells co-expressing CedV F and G proteins were visualized by Giemsa staining at $48 \mathrm{~h}$ p.t. Magnification, $\times 20 . \mathrm{n}=3$; wt: wild-type (c) Quantitative reporter gene assay. Vero76 cells were co-transfected with plasmids encoding for the CedV glycoproteins F and G as well as a plasmid containing the luciferase gene under the control of a T7 promoter (pCITE Renilla). At $24 \mathrm{~h}$ p.t., Vero76 cells expressing the T7 polymerase were layered on the glycoprotein-expressing cells and incubated for $3 \mathrm{~h}$ at $37^{\circ} \mathrm{C}$. Then, cells were lysed, and luciferase activity measured using a luminometer. Samples were tested in duplicates in three independent experiments. Reporter activity measured for the parental CedV F protein ( $\mathrm{wt} F$ ) co-transfected with CedV G protein was set to 1 serving as a reference point for fusion activity. Bars represent the fusion activities of the different (mutant) CedV F proteins in relation to the fusion activity of the parental protein and include the standard error of the mean (SEM). Background activity of the luciferase reporter was assessed with cells transfected with pCAGGS CedV G and pCITE Renilla only, layered with T7 polymerase expressing cells. $\mathrm{n}=3$.

\section{Discussion}

Endocytic uptake from the cell surface plays a particular role in the replication cycle of highly pathogenic $\mathrm{HeV}$ and NiV [11-13]. Previous work has shown the importance of endocytosis for the 
maturation of $\mathrm{F}$ proteins to gain biological activity and thus, viral infectivity $[11-13,16]$. Given the fact that endocytic uptake of $\mathrm{HeV}$ and NiV F proteins depends on tyrosine-based motifs present in their cytoplasmic tail, the comparably high number of tyrosine residues found in the CedV F protein was of interest for this study. We first aimed to investigate whether these residues indeed mediate endocytosis of the protein. Second, we analyzed whether endocytosis is of functional relevance to the CedV F protein maturation. Taken together, our data clearly indicate that endocytic uptake of CedV F protein is signal-mediated and important for the biological activity of the protein. Furthermore, among the putative endocytosis signals, we identified a $Y X X \Phi$ motif and a C-terminal di-tyrosine motif to have the strongest effects on endocytosis, cell surface expression, and fusion activity of CedV F protein.

The YXX $\Phi$ motif known to facilitate clathrin-mediated endocytosis of many transmembrane proteins is present in the membrane-proximal region of the cytoplasmic tail of both high and low

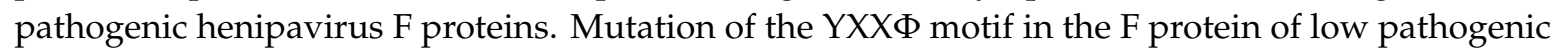
CedV resulted in a strongly decreased internalization rate for mutant e2 and e3, suggesting endocytic uptake of CedV F protein to be signal-mediated and largely dependent on this particular motif and most likely on Y524. For highly pathogenic $\mathrm{HeV}$ and NiV, several studies have similarly shown that an intact $Y X X \Phi$ motif greatly contributes to the internalization of $F$ proteins with a marked reduction in endocytosis rate upon motif disruption [11-13,43]. However, while the delayed endocytic uptake of NiV F protein led to a reduced fusogenicity of the mutant, the respective mutation in the $\mathrm{HeV} \mathrm{F}$ protein rather resulted in an enhanced cell-to-cell fusion upon interaction with the viral attachment protein $\mathrm{G}[11,12]$. Due to strong reduction but not the absence of endocytosis, the authors suggested an accumulation of recycled, fusogenic $\mathrm{HeV} F$ protein at the cell surface over time to account for the observed effects. For the respective CedV F mutants, we similarly found a clear delay in internalization (Figure 4 b), but only moderate differences in total surface expression compared to the parental CedV F protein (Figure 5). However, we did indeed measure a strong 4- to 6.5-fold increase in the fusion activity of these two mutants in contrast to the parental CedV F protein, which cannot exclusively be explained by the only slightly increased cell surface expression. Although triggering of fusion is usually thought to primarily involve the ectodomain of the fusion protein, hyper- and hypofusogenicity were also observed in NiV F cytoplasmic tail mutants due to specific mutations in a membrane-proximal polybasic KKR motif [48]. The authors explained their findings by a mutation-dependent inside-out signaling mechanism resulting in conformational changes in the $\mathrm{NiV}$ F ectodomain followed by measurable effects on the fusion activity of the protein [48]. Overall, such conformational changes of the F-ectodomain due to mutations in the cytoplasmic tail can also affect the avidity of $F$ and $G$ interaction and thus, the coordinated processes required for cell-cell fusion [48-50]. Further, it is believed that mechanisms resulting in virus entry (viral-cellular membrane fusion) and cell-cell-fusion (fusion of neighboring cell membranes) are closely related [51]. Thus, cell-cell fusion levels often correlate to viral entry levels as shown for several Hendra and Nipah glycoprotein mutants [48,52-54]. In contrast, some hyperfusogenic $\mathrm{G}$ mutants with a modified O-glycosylation were described to display reduced entry levels but similar cell-cell fusion levels [55]. Also, a headless NiV G mutant readily triggered cell-cell fusion but pseudotyped NiV virions did not enter cells [56]. Hence, the underlying mechanism for the observed hyperfusogenicity of the CedV F mutants e2 and e3 and here the potential role of Y524 will have to be addressed in future studies.

Apart from a functional YXX $\Phi$ motif, the cytoplasmic tail of CedV F protein contains two additional di-tyrosine based motifs. Mutation of the di-tyrosine motif at amino acid position $Y 533 / 534 \mathrm{~A}$ (mutant e4) showed no effect in any of the assays performed. However, mutation of the C-terminal di-tyrosine motif (Y553/554A; mutant e5 and e6) led to a detectable increase of cell surface expression with slightly enhanced fusion activity. On the one hand, this phenotype could result from a marginally reduced internalization rate. Alternatively, this di-tyrosine motif may affect the dynamics of endosomal trafficking and recycling of CedV F proteins, which could subsequently alter the availability of fusion-active F protein on the cell surface, thus having an impact on fusion activity. In a previous study, the lack of the di-tyrosine motif has been considered to delay the recycling of fusogenic NiV 
F proteins to the cell surface [43]. A tail-truncated NiV F variant lacking the C-terminal di-tyrosine motif was markedly downregulated in constitutive surface expression while F protein endocytosis and endosomal cleavage remained unaffected. Consequently, the intact di-tyrosine motif was hypothesized to act as a potential cytoplasmic recycling motif affecting intracellular trafficking [43]. Interestingly, both the YXX $\Phi$ and the C-terminal di-tyrosine motif have been described to be of importance for NiV F protein trafficking and sorting in polarized microvascular endothelial cells [57], in polarized epithelial cells [58], and in polarized neuronal cells [59].

The presence of intact tyrosine-based endocytosis and/or sorting motif in the cytoplasmic tail of transmembrane proteins has been described to be important for the replication cycle, infectivity, and virulence of many viruses such as herpes-, corona- and retroviruses [24,25,29,30,44,60,61]. Apart from signal-mediated intracellular trafficking of viral proteins to the sites of viral assembly, these motifs were shown to affect cell surface expression of different viral transmembrane proteins $[24,25,29,30,44,60,61]$. For instance, mutating the endocytosis signal of the envelope protein of simian immunodeficiency virus led to more efficient incorporation of envelope proteins into budding virions with enhanced infectivity due to increased levels of envelope protein expressed on the cell surface [61]. In the case of the CedV F protein, mutation of the di-tyrosine motif had stronger effects on the cell surface expression than mutation of the classical $Y X X \Phi$ motif. However, at this point, it is not clear whether the di-tyrosine mutants will be incorporated more efficiently into virions due to an increase in cell surface expression. Mutation of the di-tyrosine motif in the NiV F cytoplasmic tail almost completely abrogated NiV VLP budding despite the wt-like cell surface expression of the protein [62]. Additionally, the presence of an intact and functional YXX $\Phi$ endocytosis motif in the cytoplasmic tail of $\mathrm{NiV}$ and $\mathrm{HeV} F$ protein has been considered to play a critical role in endocytic trafficking and recycling, and thus, in efficient viral assembly and particle release [31,62]. Similar findings have been reported for the envelope protein of HIV-1 where recent evidence suggests that trafficking through the recycling endosome is required for efficient incorporation of viral envelope proteins into virus particles [28]. Considering the lack of an intact $Y X X \Phi$ motif, the reduced endocytosis rate, and the level of cell surface expression similar to the parental F protein, it will be interesting to see whether assembly and budding of mutant CedV F e2 and $\mathrm{e} 3$ is impaired or rather enhanced.

The most significant effects on cell surface expression, internalization rate, and fusion activity were noted for CedV mutant e7, in which all putative tyrosine-based endocytosis motifs were mutated. Importantly, the combination of all motif mutations led to an almost abrogated fusion activity of the protein with the strongest delay in internalization, which is in accordance with previous findings for a NiV F protein mutant disrupted of all tyrosine-based motifs [11]. Though CedV F mutant e7 displayed the highest cell surface expression, the combination of all mutations led to a rather reversed cleavage ratio in contrast to the other mutants. These findings point towards a reduced proteolytic $\mathrm{F}$ activation, which might result from the marked decrease in the endocytosis rate. Considering what is known for the $\mathrm{F}$ proteins of highly pathogenic $\mathrm{HeV}$ and $\mathrm{NiV}$ that are cleaved within the endosomal compartment [12-15,17], it seems likely that the proteolytic activation of CedV F protein is quite similar in terms of subcellular localization. However, future studies are needed to unravel shared commonalities and potential differences in this process.

\section{Conclusions}

In conclusion, our data indicate that CedV F protein is indeed internalized from the cell surface as described for $\mathrm{HeV}$ and NiV F proteins. Furthermore, endocytic uptake of CedV F protein is signal-mediated and represents a key step in order to gain biological activity. Future studies should investigate proteolytic activation in more detail in order to find further commonalities and/or differences in subcellular localization and protease usage between high and low pathogenic henipaviruses. Further, tyrosine-based motifs should be analyzed for their effects on sorting and endocytic trafficking of the CedV F protein including their ability to influence virus particle assembly and their potential effect on virus-cell fusion/infectivity. 
Supplementary Materials: The following are available online at http://www.mdpi.com/2073-4409/9/9/2054/s1, Figure S1: Proteolytic processing of CedV F wt and mutants e8 (e3 + e4) and e9 (e3 + e5), Figure S2: Proteolytic processing of CedV F protein is inhibited by chlorpromazine, Figure S3: Co-expression of CedV F wt, mutants and CedV G protein on the cell surface.

Author Contributions: Conceptualization, K.F. and S.D.; methodology and investigation, K.F.; analysis: K.F. and S.D.; supervision: S.D.; funding acquisition, S.D.; resources, M.H.G.; writing, K.F. and S.D. All authors have read and agreed to the published version of the manuscript.

Funding: Funding was provided by the Friedrich-Loeffler-Institut, intramural funding (S.D.) and funding as part of the VISION consortium (K.F.).

Acknowledgments: The authors wish to thank Stefanie Rößler and Carolin Rüdiger for excellent technical support and Thomas Hoenen for helpful comments and critical reading of this manuscript. The authors further acknowledge Angela Römer-Oberdörfer (pCITE) and Thomas Hoenen (pCAGGS T7) for providing the aforementioned plasmids used in this study. Many thanks to Bärbel Hammerschmidt and the animal keepers for help with the generation of polyclonal CedV F-specific serum and to Christine Luttermann for sequencing of mutants.

Conflicts of Interest: The authors declare no conflict of interest.

\section{References}

1. Marsh, G.A.; de Jong, C.; Barr, J.A.; Tachedjian, M.; Smith, C.; Middleton, D.; Yu, M.; Todd, S.; Foord, A.J.; Haring, V.; et al. Cedar Virus: A Novel Henipavirus Isolated from Australian Bats. PLoS Pathog. 2012, 8, e102836. [CrossRef]

2. Schountz, T.; Campbell, C.; Wagner, K.; Rovnak, J.; Martellaro, C.; DeBuysscher, B.L.; Feldmann, H.; Prescott, J. Differential Innate Immune Responses Elicited by Nipah Virus and Cedar Virus Correlate with Disparate In Vivo Pathogenesis in Hamsters. Viruses 2019, 11, 291. [CrossRef] [PubMed]

3. Lieu, K.G.; Marsh, G.A.; Wang, L.F.; Netter, H.J. The non-pathogenic Henipavirus Cedar paramyxovirus phosphoprotein has a compromised ability to target STAT1 and STAT2. Antivir. Res. 2015, 124, 69-76. [CrossRef] [PubMed]

4. Negrete, O.A.; Levroney, E.L.; Aguilar, H.C.; Bertolotti-Ciarlet, A.; Nazarian, R.; Tajyar, S.; Lee, B. EphrinB2 is the entry receptor for Nipah virus, an emergent deadly paramyxovirus. Nature 2005, 436, 401-405. [CrossRef]

5. Bonaparte, M.I.; Dimitrov, A.S.; Bossart, K.N.; Crameri, G.; Mungall, B.A.; Bishop, K.A.; Choudhry, V.; Dimitrov, D.S.; Wang, L.F.; Eaton, B.T.; et al. Ephrin-B2 ligand is a functional receptor for Hendra virus and Nipah virus. Proc. Natl. Acad. Sci. USA 2005, 102, 10652-10657. [CrossRef] [PubMed]

6. Negrete, O.A.; Wolf, M.C.; Aguilar, H.C.; Enterlein, S.; Wang, W.; Muhlberger, E.; Su, S.V.; Bertolotti-Ciarlet, A.; Flick, R.; Lee, B. Two key residues in ephrinB3 are critical for its use as an alternative receptor for Nipah virus. PLoS Pathog. 2006, 2, e7. [CrossRef] [PubMed]

7. Hafner, C.; Schmitz, G.; Meyer, S.; Bataille, F.; Hau, P.; Langmann, T.; Dietmaier, W.; Landthaler, M.; Vogt, T. Differential gene expression of Eph receptors and ephrins in benign human tissues and cancers. Clin. Chem. 2004, 50, 490-499. [CrossRef]

8. Pryce, R.; Azarm, K.; Rissanen, I.; Harlos, K.; Bowden, T.A.; Lee, B. A key region of molecular specificity orchestrates unique ephrin-B1 utilization by Cedar virus. Life Sci. Alliance 2020, 3. [CrossRef]

9. Laing, E.D.; Navaratnarajah, C.K.; Cheliout Da Silva, S.; Petzing, S.R.; Xu, Y.; Sterling, S.L.; Marsh, G.A.; Wang, L.F.; Amaya, M.; Nikolov, D.B.; et al. Structural and functional analyses reveal promiscuous and species specific use of ephrin receptors by Cedar virus. Proc. Natl. Acad. Sci. USA 2019, 116, 20707-20715. [CrossRef]

10. Azarm, K.D.; Lee, B. Differential Features of Fusion Activation within the Paramyxoviridae. Viruses 2020, 12, 161. [CrossRef]

11. Vogt, C.; Eickmann, M.; Diederich, S.; Moll, M.; Maisner, A. Endocytosis of the Nipah virus glycoproteins. J. Virol. 2005, 79, 3865-3872. [CrossRef] [PubMed]

12. Meulendyke, K.A.; Wurth, M.A.; McCann, R.O.; Dutch, R.E. Endocytosis plays a critical role in proteolytic processing of the Hendra virus fusion protein. J. Virol. 2005, 79, 12643-12649. [CrossRef]

13. Diederich, S.; Moll, M.; Klenk, H.D.; Maisner, A. The nipah virus fusion protein is cleaved within the endosomal compartment. J. Biol. Chem. 2005, 280, 29899-29903. [CrossRef] [PubMed]

14. Pager, C.T.; Dutch, R.E. Cathepsin L is involved in proteolytic processing of the Hendra virus fusion protein. J. Virol. 2005, 79, 12714-12720. [CrossRef] [PubMed] 
15. Pager, C.T.; Craft, W.W., Jr.; Patch, J.; Dutch, R.E. A mature and fusogenic form of the Nipah virus fusion protein requires proteolytic processing by Cathepsin L. Virology 2006, 346, 251-257. [CrossRef]

16. Diederich, S.; Thiel, L.; Maisner, A. Role of endocytosis and cathepsin-mediated activation in Nipah virus entry. Virology 2008, 375, 391-400. [CrossRef]

17. Diederich, S.; Sauerhering, L.; Weis, M.; Altmeppen, H.; Schaschke, N.; Reinheckel, T.; Erbar, S.; Maisner, A. Activation of the Nipah virus fusion protein in MDCK cells is mediated by cathepsin B within the endosome-recycling compartment. J. Virol. 2012, 86, 3736-3745. [CrossRef]

18. Matlin, K.S.; Reggio, H.; Helenius, A.; Simons, K. Infectious entry pathway of influenza virus in a canine kidney cell line. J. Cell Biol. 1981, 91, 601-613. [CrossRef]

19. Yoshimura, A.; Ohnishi, S. Uncoating of Influenza-Virus in Endosomes. J. Virol. 1984, 51, 497-504. [CrossRef]

20. Nanbo, A.; Imai, M.; Watanabe, S.; Noda, T.; Takahashi, K.; Neumann, G.; Halfmann, P.; Kawaoka, Y. Ebolavirus Is Internalized into Host Cells via Macropinocytosis in a Viral Glycoprotein-Dependent Manner. PLoS Pathog. 2010, 6, e1001121. [CrossRef]

21. Aleksandrowicz, P.; Marzi, A.; Biedenkopf, N.; Beimforde, N.; Becker, S.; Hoenen, T.; Feldmann, H.; Schnittler, H.J. Ebola Virus Enters Host Cells by Macropinocytosis and Clathrin-Mediated Endocytosis. J. Infect. Dis. 2011, 204, S957-S967. [CrossRef] [PubMed]

22. Chu, J.J.H.; $\mathrm{Ng}, \mathrm{M} . \mathrm{L}$. Infectious entry of West Nile virus occurs through a clathrin-mediated endocytic pathway. J. Virol. 2004, 78, 10543-10555. [CrossRef] [PubMed]

23. Blanchard, E.; Belouzard, S.; Goueslain, L.; Wakita, T.; Dubuisson, J.; Wychowski, C.; Rouille, Y. Hepatitis C virus entry depends on clathrin-mediated endocytosis. J. Virol. 2006, 80, 6964-6972. [CrossRef]

24. Marsh, M.; Pelchen-Matthews, A. Endocytosis in viral replication. Traffic 2000, 1, 525-532. [CrossRef] [PubMed]

25. Favoreel, H.W. The why's of Y-based motifs in alphaherpesvirus envelope proteins. Virus Res. 2006, 117, 202-208. [CrossRef] [PubMed]

26. Checkley, M.A.; Luttge, B.G.; Freed, E.O. HIV-1 envelope glycoprotein biosynthesis, trafficking, and incorporation. J. Mol. Biol. 2011, 410, 582-608. [CrossRef]

27. Postler, T.S.; Desrosiers, R.C. The tale of the long tail: The cytoplasmic domain of HIV-1 gp41. J. Virol. 2013, 87, 2-15. [CrossRef]

28. Kirschman, J.; Qi, M.; Ding, L.; Hammonds, J.; Dienger-Stambaugh, K.; Wang, J.J.; Lapierre, L.A.; Goldenring, J.R.; Spearman, P. HIV-1 Envelope Glycoprotein Trafficking through the Endosomal Recycling Compartment Is Required for Particle Incorporation. J. Virol. 2018, 92. [CrossRef]

29. Albecka, A.; Laine, R.F.; Janssen, A.F.J.; Kaminski, C.F.; Crump, C.M. HSV-1 Glycoproteins Are Delivered to Virus Assembly Sites Through Dynamin-Dependent Endocytosis. Traffic 2016, 17, 21-39. [CrossRef]

30. Beitia Ortiz de Zarate, I.; Cantero-Aguilar, L.; Longo, M.; Berlioz-Torrent, C.; Rozenberg, F. Contribution of endocytic motifs in the cytoplasmic tail of herpes simplex virus type 1 glycoprotein $\mathrm{B}$ to virus replication and cell-cell fusion. J. Virol. 2007, 81, 13889-13903. [CrossRef]

31. Cifuentes-Munoz, N.; Sun, W.; Ray, G.; Schmitt, P.T.; Webb, S.; Gibson, K.; Dutch, R.E.; Schmitt, A.P. Mutations in the Transmembrane Domain and Cytoplasmic Tail of Hendra Virus Fusion Protein Disrupt Virus-Like-Particle Assembly. J. Virol. 2017, 91. [CrossRef] [PubMed]

32. Conner, S.D.; Schmid, S.L. Regulated portals of entry into the cell. Nature 2003, 422, 37-44. [CrossRef] [PubMed]

33. Kaksonen, M.; Roux, A. Mechanisms of clathrin-mediated endocytosis. Nat. Rev. Mol. Cell Biol. 2018, 19, 313-326. [CrossRef]

34. Robinson, M.S. Forty Years of Clathrin-coated Vesicles. Traffic 2015, 16, 1210-1238. [CrossRef]

35. Bonifacino, J.S.; Traub, L.M. Signals for sorting of transmembrane proteins to endosomes and lysosomes. Annu. Rev. Biochem. 2003, 72, 395-447. [CrossRef]

36. Ohno, H.; Stewart, J.; Fournier, M.C.; Bosshart, H.; Rhee, I.; Miyatake, S.; Saito, T.; Gallusser, A.; Kirchhausen, T.; Bonifacino, J.S. Interaction of tyrosine-based sorting signals with clathrin-associated proteins. Science 1995, 269, 1872-1875. [CrossRef]

37. Reider, A.; Wendland, B. Endocytic adaptors-Social networking at the plasma membrane. J. Cell. Sci. 2011, 124, 1613-1622. [CrossRef] [PubMed]

38. Park, S.Y.; Guo, X.L. Adaptor protein complexes and intracellular transport. Biosci. Rep. 2014, 34, 381-390. [CrossRef] [PubMed] 
39. Traub, L.M. Sorting it out: AP-2 and alternate clathrin adaptors in endocytic cargo selection. J. Cell Biol. 2003, 163, 203-208. [CrossRef]

40. Le Roy, C.; Wrana, J.L. Clathrin- and non-clathrin-mediated endocytic regulation of cell signalling. Nat. Rev. Mol. Cell Biol. 2005, 6, 112-126. [CrossRef]

41. Traub, L.M. Tickets to ride: Selecting cargo for clathrin-regulated internalization. Nat. Rev. Mol. Cell Biol. 2009, 10, 583-596. [CrossRef] [PubMed]

42. Ohno, H. Clathrin-associated adaptor protein complexes. J. Cell Sci. 2006, 119, 3719-3721. [CrossRef] [PubMed]

43. Weis, M.; Maisner, A. Nipah virus fusion protein: Importance of the cytoplasmic tail for endosomal trafficking and bioactivity. Eur. J. Cell Biol. 2015, 94, 316-322. [CrossRef] [PubMed]

44. Hou, Y.; Meulia, T.; Gao, X.; Saif, L.J.; Wang, Q. Deletion of both the Tyrosine-Based Endocytosis Signal and the Endoplasmic Reticulum Retrieval Signal in the Cytoplasmic Tail of Spike Protein Attenuates Porcine Epidemic Diarrhea Virus in Pigs. J. Virol. 2019, 93. [CrossRef] [PubMed]

45. Moll, M.; Klenk, H.D.; Herrler, G.; Maisner, A. A single amino acid change in the cytoplasmic domains of measles virus glycoproteins $\mathrm{H}$ and $\mathrm{F}$ alters targeting, endocytosis, and cell fusion in polarized Madin-Darby canine kidney cells. J. Biol. Chem. 2001, 276, 17887-17894. [CrossRef] [PubMed]

46. Stroh, E.; Fischer, K.; Schwaiger, T.; Sauerhering, L.; Franzke, K.; Maisner, A.; Groschup, M.H.; Blohm, U.; Diederich, S. Henipavirus-like particles induce a CD8 T cell response in C57BL/6 mice. Vet. Microbiol. 2019, 237, 108405. [CrossRef]

47. Schneider, C.A.; Rasband, W.S.; Eliceiri, K.W. NIH Image to ImageJ: 25 years of image analysis. Nat. Methods 2012, 9, 671-675. [CrossRef]

48. Aguilar, H.C.; Matreyek, K.A.; Choi, D.Y.; Filone, C.M.; Young, S.; Lee, B. Polybasic KKR motif in the cytoplasmic tail of Nipah virus fusion protein modulates membrane fusion by inside-out signaling. J. Virol. 2007, 81, 4520-4532. [CrossRef]

49. Aguilar, H.C.; Matreyek, K.A.; Filone, C.M.; Hashimi, S.T.; Levroney, E.L.; Negrete, O.A.; Bertolotti-Ciarlet, A.; Choi, D.Y.; McHardy, I.; Fulcher, J.A.; et al. N-glycans on Nipah virus fusion protein protect against neutralization but reduce membrane fusion and viral entry. J. Virol. 2006, 80, 4878-4889. [CrossRef]

50. Carter, J.R.; Pager, C.T.; Fowler, S.D.; Dutch, R.E. Role of N-linked glycosylation of the Hendra virus fusion protein. J. Virol. 2005, 79, 7922-7925. [CrossRef]

51. White, J.M.; Delos, S.E.; Brecher, M.; Schornberg, K. Structures and mechanisms of viral membrane fusion proteins: Multiple variations on a common theme. Crit. Rev. Biochem. Mol. Biol. 2008, 43, 189-219. [CrossRef] [PubMed]

52. Biering, S.B.; Huang, A.; Vu, A.T.; Robinson, L.R.; Bradel-Tretheway, B.; Choi, E.; Lee, B.; Aguilar, H.C. N-Glycans on the Nipah virus attachment glycoprotein modulate fusion and viral entry as they protect against antibody neutralization. J. Virol. 2012, 86, 11991-12002. [CrossRef] [PubMed]

53. Bradel-Tretheway, B.G.; Liu, Q.; Stone, J.A.; McInally, S.; Aguilar, H.C. Novel Functions of Hendra Virus G N-Glycans and Comparisons to Nipah Virus. J. Virol. 2015, 89, 7235-7247. [CrossRef] [PubMed]

54. Liu, Q.; Bradel-Tretheway, B.; Monreal, A.I.; Saludes, J.P.; Lu, X.; Nicola, A.V.; Aguilar, H.C. Nipah virus attachment glycoprotein stalk C-terminal region links receptor binding to fusion triggering. J. Virol. 2015, 89, 1838-1850. [CrossRef] [PubMed]

55. Stone, J.A.; Nicola, A.V.; Baum, L.G.; Aguilar, H.C. Multiple Novel Functions of Henipavirus O-glycans: The First O-glycan Functions Identified in the Paramyxovirus Family. PLoS Pathog. 2016, 12, e1005445. [CrossRef]

56. Liu, Q.; Stone, J.A.; Bradel-Tretheway, B.; Dabundo, J.; Benavides Montano, J.A.; Santos-Montanez, J.; Biering, S.B.; Nicola, A.V.; Iorio, R.M.; Lu, X.; et al. Unraveling a three-step spatiotemporal mechanism of triggering of receptor-induced Nipah virus fusion and cell entry. PLoS Pathog. 2013, 9, e1003770. [CrossRef]

57. Erbar, S.; Maisner, A. Nipah virus infection and glycoprotein targeting in endothelial cells. Virol. J. 2010, 7, 305. [CrossRef]

58. Weise, C.; Erbar, S.; Lamp, B.; Vogt, C.; Diederich, S.; Maisner, A. Tyrosine residues in the cytoplasmic domains affect sorting and fusion activity of the Nipah virus glycoproteins in polarized epithelial cells. J. Virol. 2010, 84, 7634-7641. [CrossRef]

59. Mattera, R.; Farias, G.G.; Mardones, G.A.; Bonifacino, J.S. Co-assembly of viral envelope glycoproteins regulates their polarized sorting in neurons. PLoS Pathog. 2014, 10, e1004107. [CrossRef] [PubMed] 
60. Day, J.R.; Munk, C.; Guatelli, J.C. The membrane-proximal tyrosine-based sorting signal of human immunodeficiency virus type $1 \mathrm{gp} 41$ is required for optimal viral infectivity. J. Virol. 2004, 78, 1069-1079. [CrossRef] [PubMed]

61. Yuste, E.; Reeves, J.D.; Doms, R.W.; Desrosiers, R.C. Modulation of Env content in virions of simian immunodeficiency virus: Correlation with cell surface expression and virion infectivity. J. Virol. 2004, 78, 6775-6785. [CrossRef] [PubMed]

62. Johnston, G.P.; Contreras, E.M.; Dabundo, J.; Henderson, B.A.; Matz, K.M.; Ortega, V.; Ramirez, A.; Park, A.; Aguilar, H.C. Cytoplasmic Motifs in the Nipah Virus Fusion Protein Modulate Virus Particle Assembly and Egress. J. Virol. 2017, 91. [CrossRef] [PubMed]

(C) 2020 by the authors. Licensee MDPI, Basel, Switzerland. This article is an open access article distributed under the terms and conditions of the Creative Commons Attribution (CC BY) license (http://creativecommons.org/licenses/by/4.0/). 